\title{
Commentary: Coming to terms with stroke and "brain lesions" in cardiac surgery
}

\author{
Keshava Rajagopal, MD, $\mathrm{PhD}$
}

\author{
From the Department of Advanced Cardiopulmonary Therapies and Transplantation, McGovern Medical School, \\ University of Texas-Houston, Houston, Tex. \\ Disclosures: Author has nothing to disclose with regard to commercial support. \\ Received for publication Sept 28, 2019; revisions received Sept 28, 2019; accepted for publication Sept 29, 2019; \\ available ahead of print Oct 10, 2019. \\ Address for reprints: Keshava Rajagopal, MD, PhD, 6400 Fannin, Suite 2350, Houston, TX 77030 (E-mail: \\ keshava.rajagopal@uth.tmc.edu). \\ J Thorac Cardiovasc Surg 2021;161:647-8 \\ $0022-5223 / \$ 36.00$ \\ Copyright (c) 2019 by The American Association for Thoracic Surgery \\ https://doi.org/10.1016/j.jtcvs.2019.09.143
}

Medical terminology often is confusing. Examples of inexactness abound, extending even to the flagrantly incorrect. For example, the "air-fluid level." An elementary introduction to the phases of matter teaches us that gases and liquids are both fluids, and as air is a fluid, the aforementioned term is absurd.

What is stroke? Ischemic necrosis, also known as infarction, may occur in the cells of any vascularized tissue. Stroke may be operationally defined as infarction within the central nervous system, whether the underlying etiology is due to impaired arterial supply or hemorrhage causing a local compartment syndrome and capillary-level ischemia. ${ }^{1}$ The gold standard for diagnosing infarction is histologic assessment, whether this does or does not correlate with larger-scale tissue/organ dysfunction. However, this is rarely clinically feasible, and biochemical (eg, cardiac biomarkers) and/or physiological (eg, echocardiography and/or electrocardiography) indices of infarction must be used to establish diagnoses and initiate therapies. It is important to separate diagnostic criteria for infarction, from actual infarction itself, and this in turn from the functional sequelae of infarction. These 3 entities correlate with one another, but imperfectly and nonlinearly so.

In the case of brain infarction, even less information is available. Imaging studies demonstrating "ischemic changes" or "brain lesions," and the historically classical tools of history and physical examination, typically make the diagnosis of stroke. With these issues in mind, in this issue of the Journal, Tachibana and colleagues ${ }^{2}$ report the results of a prospectively conducted study of postoperative versus preoperative magnetic resonance imaging of the brain in 108 patients undergoing elective, first-time isolated coronary artery bypass grafting (CABG). CABG with cardiopulmonary bypass (ON-CABG) was performed in 39 patients, whereas $\mathrm{CABG}$ without cardiopulmonary bypass (OP-CABG) was performed in 65 patients.

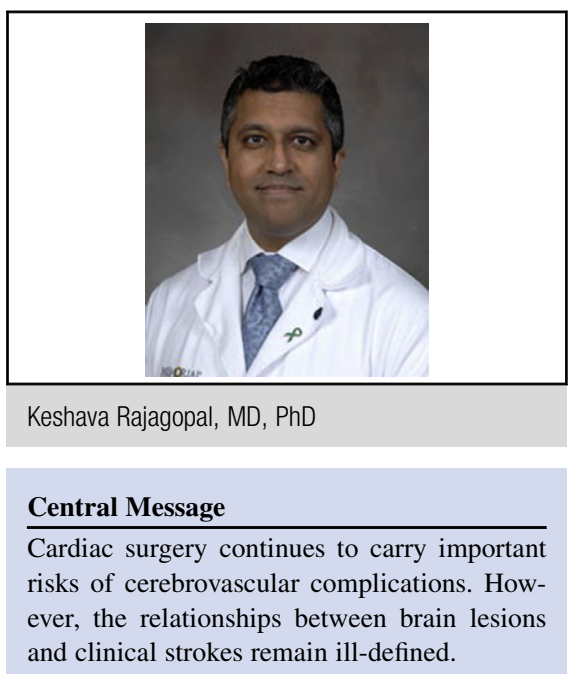

See Article page 636.

Clinically obvious stroke occurred in 1 patient who underwent OP-CABG. However, approximately $20 \%$ of patients had evidence of new brain lesions on magnetic resonance imaging. Patients with brain lesions more commonly had evidence of ascending thoracic aortic atherosclerosis, underwent $\mathrm{ON}-\mathrm{CABG}$, and underwent some type of aortic clamping. However, a significant "baseline" rate of brain lesions was identified in patients who underwent OP-CABG, and even in the subset of patients designated as OP-CABG undergoing anaortic surgery $(12.3 \%$ of OP-CABG; $15.8 \%$ of anaortic). The presence of multiple brain lesions correlated with the postoperative cognitive dysfunction.

Although the data are clear, how to interpret them is not. Do brain lesions represent actual loci of strokes? If they do, are potential functional sequelae truly correlated with the lesions (and if so, should such lesions even be termed "silent," since have demonstrable sequelae, even if it takes some effort to identify them)? Do sequelae relate to size (ie, extent of infarction) and location of lesions? Finally, given the significant incidence of brain lesions even when measures have been taken to eliminate or minimize aortic manipulation, do we need to take additional measures to minimize the development of brain lesions (eg, embolic protection devices)? Further studies will be required to answer these questions, but this work is an important start. 


\section{References}

1. Sacco RL, Kasner SE, Broderick JP, Caplan LR, Connors JJ, Culebras A, et al. An updated definition of stroke for the 21st century: a statement for healthcare professionals from the American Heart Association/American Stroke Association. Stroke. 2013;44:2064-89.
2. Tachibana H, Hiraoka A, Saito K, Naito Y, Chikazawa G, Tamura K, et al. Incidence and impact of silent brain lesions after coronary artery bypass grafting. $J$ Thorac Cardiovasc Surg. 2021;161:636-44. 